\title{
Effects of disturbance on the diversity of hard-bottom macrobenthic communities on the coast of Chile
}

\author{
Nelson Valdivia ${ }^{1}$, Astrid Heidemann², Martin Thiel ${ }^{1,3}$, Markus Molis $^{4,5, *}$, \\ Martin Wahl ${ }^{4}$ \\ ${ }^{1}$ Facultad de Ciencias de Mar, Universidad Católica del Norte, Larrondo 1281, Coquimbo, Chile \\ ${ }^{2}$ Institute for Biology and Environmental Science, Carl von Ossietzky University, Ammerländer Heerstr. 114-118, \\ 26129 Oldenburg, Germany \\ ${ }^{3}$ Centro de Estudios Avanzados en Zonas Áridas (CEAZA), Coquimbo, Chile \\ ${ }^{4}$ Leibniz-Institute for Marine Science, Düsternbrooker Weg 20, 24105 Kiel, Germany
}

${ }^{5}$ Present address: Foundation Alfred Wegener Institute for Polar and Marine Research, Biological Station Helgoland, Kurpromenade 201, 27498 Helgoland, Germany

\begin{abstract}
The intermediate disturbance hypothesis (IDH) predicts maximal diversity at intermediate levels of disturbance, but the validity of this hypothesis is controversially discussed. In this study, results of a field experiment, which was conducted on the northern-central Chilean coast, are presented. Fouling communities on artificial settlement substrata were studied. A total of 7 disturbance frequencies were applied to previously established communities, and a single disturbance event resulted in a removal of $\sim 20 \%$ of the biomass. Species cover was estimated at the end of the experimental period, and it was found that diversity was strongly affected by disturbance frequency. With high disturbance frequencies the composition of the community was changed, with a decrease in the solitary ascidian Pyura chilensis (Molina 1782). The decrease of $P$. chilensis resulted in an increase of the colonial ascidian Diplosoma sp. A unimodal relationship between disturbance frequency and species richness was found, supporting the IDH. The results suggest that disturbance sustains diversity by reducing the abundance of the dominant species (e.g. P. chilensis), preventing competitive exclusion of the subordinate species, thus allowing subordinate species to re-emerge when competition is alleviated by disturbance. The results also suggest that these species show a trade-off between competitive and colonizing abilities, pointing to the existence of a competitive hierarchy. Therefore, the presence of competitive exclusion and disturbance-induced suppression of the dominant species remains a crucial mechanism, permitting species coexistence in the context of the IDH in the system studied.
\end{abstract}

KEY WORDS: Disturbance-diversity relationship · Intermediate disturbance hypothesis · Disturbance $\cdot$ Competitive exclusion $\cdot$ Frequency $\cdot$ Sessile $\cdot$ Hard-bottom $\cdot$ Pyura chilensis

\section{INTRODUCTION}

The intermediate disturbance hypothesis (IDH, Connell 1978) attempts to explain biological diversity and species coexistence by using a non-equilibrium model. It predicts that in the absence of disturbance, species diversity is depressed due to competitive exclusion of inferior competitors by one or a few dominant species. Likewise, species diversity is predicted to decline under harsh (very frequent or intense) disturbance regimes, because few species are able to survive or settle successfully. At intermediate levels of disturbance, maximal diversity is sustained via compensatory mortality. This concept assumes a disproportion- 
ately higher effect of disturbance on the abundance of superior rather than inferior competitors (Petraitis et al. 1989). Following White \& Pickett (1985), a disturbance 'changes resources, substrate availability, or the physical environment'. In order to affect the community structure, a disturbance must change limiting resources. In hard-bottom communities, the limiting resource may often be settlement substratum (Connell 1961, Buss 1979, Buss \& Jackson 1979, Connolly \& Muko 2003).

Although previous studies have found peaks of diversity at intermediate disturbance levels (Lubchenco 1978, Paine \& Levin 1981, Thorp \& Cothran 1984, Aronson \& Precht 1995, Flöder \& Sommer 1999), several other publications do not support the IDH (Mook 1981, Death \& Winterbourn 1995, Mackey \& Currie 2000, McCabe \& Gotelli 2000, reviewed in Mackey \& Currie 2001). The IDH depends on a tradeoff between competitive and colonizing abilities, which is suggested to affect the immigration and extinction rates of a patch (Petraitis et al. 1989). Such an assumption requires that a superior competitor has a low colonization rate (Tilman 1994, Yu \& Wilson 2001). This could be applicable in systems where competition for space is important (e.g. marine hardbottom communities), but in contrast, it is not realistic in systems with highly mobile species, such as streamdwelling organisms (Lake et al. 1989, McCabe \& Gotelli 2000), which can rapidly invade previously disturbed patches (Thorp \& Cothran 1984). However, several other factors must be taken into consideration when examining non-linear patterns in diversity. These include variations in the sampling intensity (Mackey \& Currie 2000) and differences in productivity levels (Proulx \& Mazumder 1998, Kondoh 2001). In highly productive systems, dominant species may grow very rapidly and therefore competitive exclusion may occur during early stages of succession.

Chilean nearshore waters are characterized by high biological productivity (Acuña et al. 1989, Wieters et al. 2003). These high productivity levels could be linked with high growth rates of competing species (Huston 1979), and a high potential for competitive exclusion. Previous studies on consumer-food interactions have already indicated that dominant competitors suppress populations of subordinate organisms in these systems (Navarrete \& Castilla 2003, Nielsen \& Navarrete 2004). These features make the Chilean coast an ideal place to test the validity of the IDH in hard-bottom communities.

This study examined the effects of disturbance frequency on species diversity and assemblages in a hard-bottom marine community on the northerncentral coast of Chile. Diversity was surveyed while disturbance frequency was manipulated in a field experiment with artificial settlement substratum. The macrobenthic sessile community was primarily composed of suspension-feeders and primary producers. Thus, difficulties that could arise when testing the IDH in multi-trophic communities (Wootton 1998) were avoided. The survey examined if (1) there was a relationship between disturbance and species richness and evenness, and (2) this relationship was unimodal as predicted by the IDH. Based on our results, we aim to evaluate whether these patterns are caused by competitive exclusion and disturbance-induced suppression of the dominant species.

\section{MATERIALS AND METHODS}

Study site. The experiment was conducted in Bahía La Herradura, a sheltered bay of $3.3 \mathrm{~km}^{2}$, on the northern-central coast of Chile at Coquimbo (29 $58^{\prime} 30^{\prime \prime} \mathrm{S}$, $71^{\circ} 22^{\prime} 30^{\prime \prime}$ W). Bahía La Herradura is a semi-enclosed bay affected by local upwelling areas. The main upwelling area is located at a distance of approximately $40 \mathrm{~km}$ southwest of the study area (Acuña et al. 1989). The main subsurface source of upwelling off northern Chile is the subsurface equatorial water (Morales et al. 1996), which is characterized as being relatively cold, oxygen-poor water, with a high nutrient content (Silva \& Konow 1975), leading to the high productivity of this coastal region (Acuña et al. 1989, Daneri et al. 2000, Takesue et al. 2004).

The surface water temperature in Bahía La Herradura varies between $13^{\circ} \mathrm{C}$ in winter and $20^{\circ} \mathrm{C}$ in summer (Moraga \& Olivares 1993). Water depth at the study side was approximately 7 to $8 \mathrm{~m}$, and the sediment below the experimental set-up consisted of coarse-grained sand. Large boulders covered with red and green macroalgae characterize shallow hardbottoms in the bay and bare rock substrata are also present. Buoys, piers, suspended culture systems, and other marine facilities provide habitat for dense assemblages of ascidians, especially the solitary ascidian Pyura chilensis.

Experimental design and set-up. The temporal dynamics of a field-grown macrobenthic sessile community were examined under experimentally manipulated disturbance regimes. Seven disturbance treatments were arranged in a randomized block design. To estimate variability within blocks, there was 1 extra replicate of 2 treatments in each of the 15 blocks (Underwood 1997).

A total of 15 moorings were installed at the beginning of the experiment and each mooring positioned a ring of grey PVC (60 cm diameter, $25 \mathrm{~cm}$ high) approximately $1 \mathrm{~m}$ below the water surface. PVC panels of $15 \times 15 \mathrm{~cm}$ were used as artificial settlement substrata 
Nine panels were fixed to the inner surface of each PVC ring with cable ties. The cable ties allowed reversible detachment of panels. The surface of each panel facing the center of the ring was roughened with sandpaper (grading No. 60).

The experiment was conducted between August 2003 and April 2004. During the first 13 wk (August to November, maturing phase), the panels were exposed to natural colonization without manipulation. At the end of this phase, the sessile macrobenthic community of 2 randomly chosen panels on each ring was sampled (14 to 15 November). This was done to obtain information about the species diversity in this early-successional community under natural disturbance conditions. Disturbance treatments were initiated after this survey. Treatments were allocated randomly to the panels of each ring in such a way that every treatment appeared at least once within each ring, with 1 extra replicate of 2 of the treatments. Subsequently, all panels were sampled 3 times, 21, 29, and $36 \mathrm{wk}$ after the initiation of the experiment (7-9 January, 1-3 March, 24-25 April 2004).

Disturbance treatments. Disturbance was defined as an event that changes niche opportunities (Shea et al. 2004), i.e. removal of biomass to free up resources for other organisms (Grime 1977). Disturbance frequency was manipulated at 7 levels, while spatial extension and intensity of individual disturbances were constant. For each disturbance manipulation, biomass was cleared in 2 non-overlapping circular patches of equal size. This resulted in a total loss of biomass from $20 \%$ of the community. The position of each patch was assigned randomly for each disturbance manipulation using a grid of 25 possible positions. This grid included the whole panel, and consequently, any of the 25 possible positions could have been disturbed more than once throughout the 6 mo experimental phase. Panels of different treatment levels were disturbed $0,2,3,4,5$, 7 , and 12 times throughout the experimental phase. Disturbance events were distributed homogeneously throughout the experiment and each panel contained a mosaic of patches of different ages. This counteracts the potentially confounding effects of disturbance frequency and time since last disturbance by the 'build up' of several disturbance events. Disturbance manipulations were scheduled every $2 \mathrm{wk}$. To conduct the manipulations, rings were lifted out of the water for a maximum of $20 \mathrm{~min}$.

Sampling. Rings were brought to shore and the panels were cut loose for non-destructive sampling of the community on the panels. Care was taken that panels were constantly submerged and protected from direct sun exposure. The percentage cover of each species of the sessile macrobenthic (>1 mm) community, including epibionts, was estimated by the naked eye, on the inner $13 \times 13 \mathrm{~cm}$, in order to reduce effects of the margin. A regular grid was used to facilitate the estimation. Percentage cover of some smaller sessile organisms such as benthic diatoms were also recorded, but excluded from further analysis in order to avoid potential problems, which could be caused by comparisons of organisms from very different size spectra. Percentage cover was estimated at $5 \%$ intervals, and species covering less than $5 \%$ were recorded as $1 \%$ (i.e. present). Panels were also checked with a dissecting microscope (magnification 5 to $6.5 \times$ ) to ensure that no species were missed in the sampling process. Due to the multilayered structure of the community, total cover could exceed $100 \%$, but cover of single species had a maximum of $100 \%$. Cross-comparisons between the estimates of both observers were conducted and no significant differences were found. During sampling events, the rings and attached ropes were cleaned of fouling organisms. The panels were then returned to the rings and re-submerged. Rings were removed from the water for a maximum of $2 \mathrm{~h}$ to reduce handling and exposure of the panels. After the final sampling (Week 36), the entire fouling community was scraped off the panels and dried in a drying stove at $60^{\circ} \mathrm{C}$ until the weight stabilized and the weight of dry biomass was recorded.

Data analysis. Statistical analysis was carried out on the data obtained after Week 36, and data from previous sampling dates are shown for comparative purposes only. Species richness, evenness, total percentage cover and dry mass were analyzed as dependent variables. Total percentage cover data were arcsine transformed for all statistical analysis. Two panels of different treatments were lost during the experimental phase, but given the large replication ( $n \geq 18$ ), no substitutes were created and the replicates of the remaining treatments were not reduced, consequently analyses were run unbalanced.

Two-way mixed model ANOVA (type III) was used to test for the effects of disturbance treatments (fixed factor) and rings (blocks; random factor) on the dependent variables. Due to the unbalanced design, Satterthwaite's approximations were utilized to calculate the $F$ ratios (Satterthwaite 1946, Zar 1999). Hochberg's GT2 was used as a post-hoc test as variances were homogenous. Data were modeled with regression analysis and linear and quadratic models were tested in sequential and independent regression analyses. These analyses were computed using orthogonal polynomials as part of the ANOVA table (Sokal \& Rohlf 1995). For the regressions, treatment groups were classified by the total number of disturbance events and used as independent variables. In this way, correct scaling of treatment groups was achieved.

Effects of treatment on species composition (i.e. percentage cover data for all species on all panels) were 
investigated with 1-way ANOSIM (a non-parametric procedure, which uses the difference between average ranked Bray-Curtis dissimilarity values among replicates, between samples and within samples, to calculate the $R$ statistic). If $R$ was significantly different from 0 at the 0.05 probability level, pair wise comparisons were used to identify which treatment levels differed. Subsequent SIMPER routine revealed the contribution of single species to these dissimilarities. ANOSIM and SIMPER analyses were performed using PRIMER 5 software package (Plymouth Marine Laboratory).

\section{RESULTS}

\section{Species richness}

Species richness declined towards the end of the experiment when compared to the start communities (Fig. 1). At Week 36, species richness was low compared to the start communities for control, low and high disturbance frequencies (Fig. 1).

Disturbance treatments had a significant effect on species richness (ANOVA, $p=0.001$, Table 1). Panels that were disturbed never (control) or twice over 6 mo hosted fewer species than panels that were intermediately disturbed (Hochberg's GT2 post-hoc test, Fig. 1). On panels that were most frequently disturbed, species richness declined compared to the intermediate disturbance frequency, but differences were not significant (Hochberg's GT2 post-hoc test, Fig. 1). Regression analysis showed significant quadratic, but not linear models (sequential regressions, $p=0.000$ for quadratic; $p=0.086$ for linear, Table 1 ), and therefore points to a unimodal relationship between disturbance frequency and species richness, which is skewed to the right.

Table 1. Results of the 2-way mixed model ANOVA (type III) and sequential regression analyses on the response variable species richness. Fixed factor: disturbance frequency. Random factor: block. Variances were homogeneous (Cochran's test, p > 0.05). ${ }^{*}$ F-ratio was calculated by using Satterthwaite's approximations. Numerator $=$ MS (Disturbance) denominator $=0.933 \mathrm{MS}($ Dist. $\times$ Block $)+0.06684 \mathrm{MS}($ Error $)$

\begin{tabular}{|lrrrr|}
\hline Source & df & MS & \multicolumn{1}{c|}{$F$} & $\mathrm{p}$ \\
\hline Disturbance (Dist.) & 6 & 12.13 & $4.44^{*}$ & 0.001 \\
$\quad$ Linear & 1 & 7.65 & 3.17 & 0.086 \\
Quadratic & 1 & 50.79 & 21.07 & 0.000 \\
Residual & 4 & 3.59 & & \\
Block & 14 & 5.14 & & \\
Dist. $\times$ Block & 84 & 2.73 & & \\
Error & 28 & 2.41 & & \\
\hline
\end{tabular}

\section{Evenness}

Evenness was significantly affected by disturbance frequency (ANOVA, p =0.000, Table 2). Evenness was lower for panels disturbed 0 or twice throughout the experimental period than for panels disturbed under intermediate or high disturbance frequencies (Hochberg's GT2 post-hoc test, Fig. 2). Evenness slightly decreased from panels of the second highest towards panels of the highest disturbance frequency, but this trend was not significant (Hochberg's GT2 post-hoc

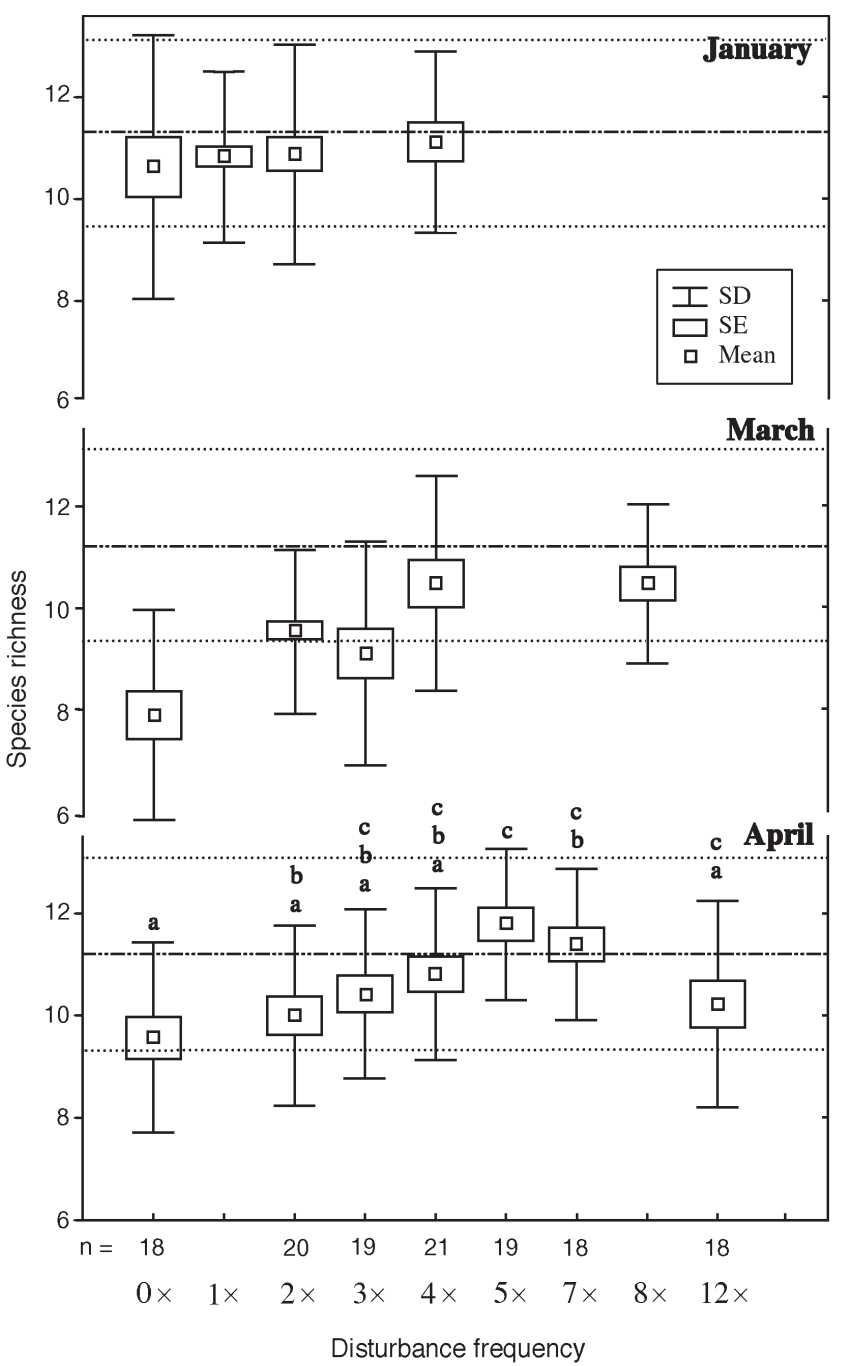

Fig. 1. Effects of disturbance frequency on species richness for each sampling event. Treatment groups on the $X$-axis are characterized by the number of disturbance events over the experimental phase $(6 \mathrm{mo})$. Dashed lines represent mean species richness and dotted lines represent \pm SD observed in November 2003 before the start of disturbance treatments. For data from January and March, no statistical analysis was performed. For April, $n$ of replicates is shown. Treatment groups with the same superscript letter are not statistically different from each other (Hochberg's GT2 post-hoc test, p > 0.05) 
Table 2. Results of the 2-way mixed model ANOVA (type III) and sequential regression analyses on the response variable evenness. Fixed factor: disturbance frequency. Random factor: block. Variances were homogeneous (Cochran's test, $\mathrm{p}>0.05) .{ }^{*}$ F-ratio calculated as for Table 1

\begin{tabular}{|lrrrr|}
\hline Source & df & MS & \multicolumn{1}{c|}{$F$} & $\mathrm{p}$ \\
\hline Disturbance (Dist.) & 6 & 0.10 & $8.01^{*}$ & 0.000 \\
$\quad$ Linear & 1 & 0.49 & 33.69 & 0.000 \\
Quadratic & 1 & 0.12 & 8.23 & 0.007 \\
Residual & 4 & 0.00 & & \\
Block & 14 & 0.01 & & \\
Dist. $\times$ Block & 84 & 0.01 & & \\
Error & 28 & 0.01 & & \\
\hline
\end{tabular}

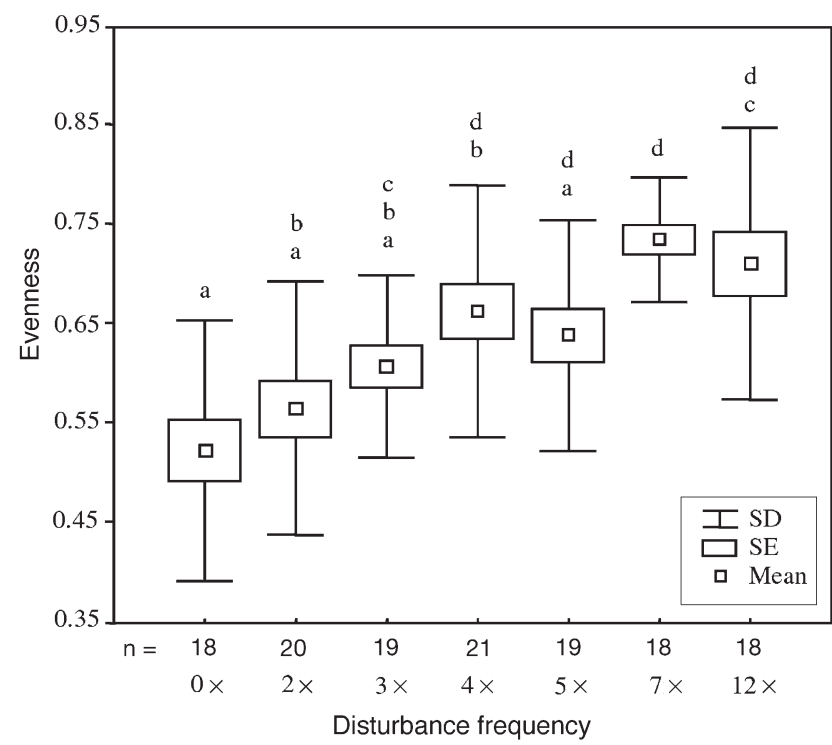

Fig. 2. Effects of disturbance frequency on evenness. Characterization of treatment groups on the $x$-axis and superscript letter code as in Fig. 1

test, Fig. 2). Regression analyses for both the linear and the quadratic model were significant (Sequential regression, $p=0.000$ for linear; $p=0.007$ for quadratic, Table 2). Therefore, the relationship between disturbance frequency and evenness can be seen as either positive or skewed unimodal.

\section{Community composition}

In total 30 macrobenthic species were identified (Table 3). Red encrusting algae were also found covering up to $5 \%$ of the panel surface, but could not be identified (Table 3). Most of the species were suspensionfeeders. In accordance with the results of ANOVA and
Table 3. List of species found on the panels. Note: panels were sampled and therefore species could only be recorded in Week 13, 21, 29, and 36

\begin{tabular}{|c|c|}
\hline Species & $\begin{array}{l}\text { Week of first } \\
\text { appearance }\end{array}$ \\
\hline \multicolumn{2}{|l|}{ Ascidians } \\
\hline \multicolumn{2}{|l|}{ Solitary } \\
\hline Pyura chilensis (Molina 1782) & 13 \\
\hline Ciona intestinalis (L. 1767) & 13 \\
\hline Unidentified tunicate & 13 \\
\hline \multicolumn{2}{|l|}{ Colonial } \\
\hline Diplosoma sp. & 13 \\
\hline Botryllus schlosseri (Pallas 1776) & 13 \\
\hline Lissoclinum sp. & 29 \\
\hline Aplidium sp. & 36 \\
\hline \multicolumn{2}{|l|}{ Bryozoans } \\
\hline Bugula neritina (L. 1758) & 13 \\
\hline Bugula flabellata (Johnston in Gray 1848) & 13 \\
\hline Membranipora isabelleana (d'Orbigny 1847) & 13 \\
\hline Alcyonidium sp. & 13 \\
\hline Unidentified bryozoan & 13 \\
\hline \multicolumn{2}{|l|}{ Hydroids } \\
\hline Obelia sp. & 13 \\
\hline Plumularia setacea c.f. (L. 1758) & 13 \\
\hline Tubularia sp. & 29 \\
\hline \multicolumn{2}{|l|}{ Algae } \\
\hline Ulva sp. A & 13 \\
\hline Ulva sp. B & 13 \\
\hline \multicolumn{2}{|l|}{ Polysiphonia mollis (Hooker \& Harvey } \\
\hline in Harvey 1847) & 13 \\
\hline Polysiphonia sp. & 13 \\
\hline Antithamnion densum (Suhr) Howe 1914 & 13 \\
\hline Unidentified red encrusting algae & 13 \\
\hline Phaeophyceae sp. & 13 \\
\hline Ectocarpaceae sp. & 21 \\
\hline Corallina sp. & 21 \\
\hline \multicolumn{2}{|l|}{ Others } \\
\hline Austromegabalanus psittacus (Molina 1782) & 13 \\
\hline Lepas anatifera (L. 1767) & 13 \\
\hline Crepidula spp. & 13 \\
\hline Semimytilus algosus (Gould 1850) & 29 \\
\hline Leucosolenia variabilis (Haeckel 1870) & 21 \\
\hline Unidentified Demospongiae & 13 \\
\hline Phymactis clematis (Drayton 1798) & 36 \\
\hline
\end{tabular}

regression analyses, community composition was different on panels of different disturbance frequencies, leading to significant dissimilarities between these treatment groups (ANOSIM, Global $R=0.224, \mathrm{p}=0.001$ ). Pairwise comparisons between treatment groups revealed that each disturbance group differed from almost all other disturbance groups (ANOSIM pairwise comparisons, for each combination of group's $\mathrm{p} \leq 0.05$ ). Exceptions were the adjacent groups with most similar disturbance frequencies: control panels did not differ significantly from those disturbed twice. In the same way, panels that were disturbed 2 and 3 times, 3 and 4 times, 3 and 5 times and 4 and 5 times showed no significant differences between them. For each significant pair of groups the 2 most common species, the soli- 
tary ascidian Pyura chilensis and the colonial ascidian Diplosoma sp. accounted for at least $50 \%$ of the variation (SIMPERanalysis). P. chilensis accounted for $38 \%$ of the dissimilarities between control and panels of the highest disturbance frequency. Other species explained only minor parts of the inbetween group dissimilarities.

\section{Total percentage cover and dry mass}

Mean total percentage cover decreased significantly with increasing disturbance frequency from approximately 140 to $60 \%$. (ANOVA, $p=0.000$, Table 4, Fig. 3). At the same time, bare space increased from $<3$ to $>20 \%$. For the highest disturbance frequencies the amount of bare space is smaller than could have been expected from total percentage cover data. This discrepancy arises because parts of the panels were covered by benthic diatoms or tube-building amphipods, which were not included in the analysis.

Abundance of Pyura chilensis was negatively related to disturbance frequency. Between controls and panels of the highest disturbance frequency, cover of $P$. chilensis declined by $75 \%$. Diplosoma sp. increased from 17 to $22 \%$ cover between the same disturbance frequencies (Fig. 3). Diplosoma sp. was therefore more common on panels with higher disturbance frequencies, whereas $P$. chilensis was more abundant on panels with low disturbance frequencies (Fig. 3).

Mean dry mass declined significantly with increasing disturbance frequency from 110 to $25 \mathrm{~g}$ (ANOVA,

Table 4. Results of the 2-way mixed model ANOVA (type III) on the response variables total percentage cover and dry mass. Fixed factor: disturbance frequency. Random factor: block. Variances were homogeneous (Cochran's test, p > $0.05) .{ }^{*} F$-ratio calculates as Table 1

\begin{tabular}{|lrrrr|}
\hline Source & df & \multicolumn{1}{c|}{ MS } & $F$ & p \\
\hline Total Percent Cover & & & & \\
Disturbance (Dist.) & 6 & 998.09 & $16.99^{*}$ & 0.000 \\
Block & 14 & 62.30 & & \\
Dist. $\times$ Block & 84 & 58.71 & & \\
Error & 28 & 35.79 & & \\
Dry mass & & & & \\
Dist. & 6 & 11949.52 & $16.46^{*}$ & 0.000 \\
Block & 14 & 2147.70 & & \\
Dist. $\times$ Block & 84 & 725.83 & & \\
Error & 28 & 1041.14 & & \\
\hline
\end{tabular}

$p=0.000$, Table 4, Fig. 4). The changes in total abundance and dry mass among treatment levels are a direct result of disturbance treatments and therefore confirm their effectiveness.

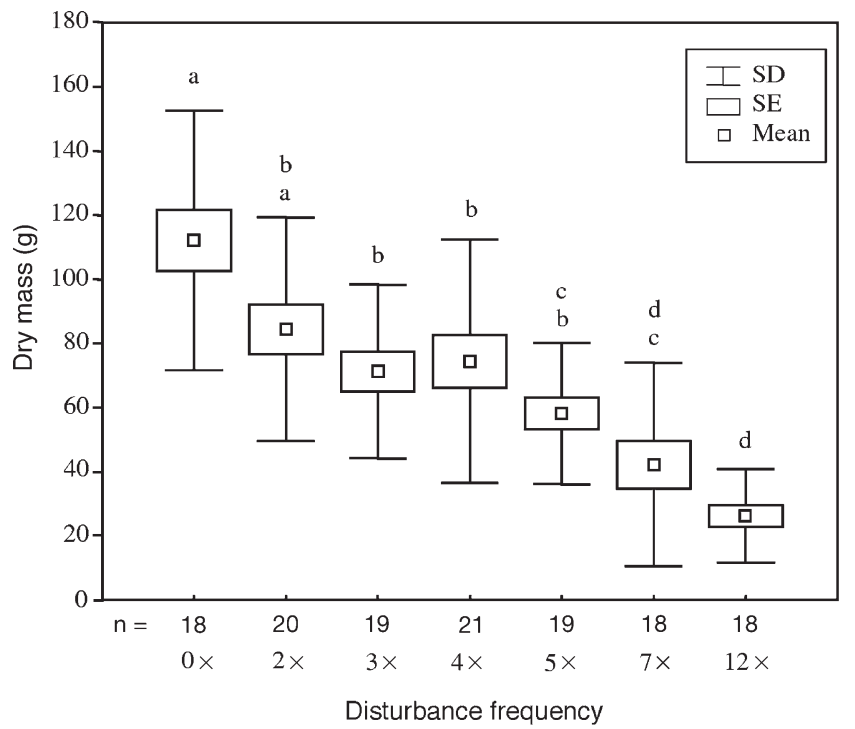

Fig. 4. Effects of disturbance frequency on dry mass (g). Characterization of treatment groups on the $x$-axis and superscript letter code as in Fig. 1 


\section{DISCUSSION}

Diversity was strongly affected by disturbance treatments. Changes in community composition were mainly due to the decrease of the solitary ascidian Pyura chilensis. A decrease in coverage of $P$. chilensis resulted in an increase of the colonial ascidian Diplosoma sp. The results show a unimodal relationship between disturbance frequency and species richness, which was strongly skewed towards high disturbance frequencies. Reduced levels of diversity under low disturbance frequencies suggest that competitive exclusion was operating. Disturbance generates conditions in which subordinate species can re-emerge in abundance when competition is alleviated. The characteristics of the competing species suggest that a trade-off between the competitive and colonizing abilities of these species exists, pointing to a competitive hierarchy. These results contrast with the low experimental support of the IDH reported in a recent review (Mackey \& Currie 2001). This suggests that the IDH is only applicable in systems and/or conditions where competitive exclusion is evident and where disturbance events suppress dominant competitors.

\section{Diversity increases from low and intermediate towards higher disturbance frequencies}

Species richness and evenness increased with an increase in disturbance frequency up to 5 times over 6 mo. This suggests that at low disturbance frequencies the community was dominated by few species. Species richness on the control and low disturbance frequency panels at the end of the experiment was lower than in the start communities, pointing to the presence of competitive exclusion. Where disturbances seldom occur, competition among species is most important in determining community structure (Connell 1978, Miller 1982). In space-limited sessile macrobenthic communities, competition mainly consists in the ability to occupy space and hold it against invaders (Connell \& Keough 1985). Abundance of Pyura chilensis was high across almost all disturbance levels, but its dominance was strongest under low disturbance frequencies. Recruitment rates of $P$. chilensis are known to be low in comparison to other fouling organisms in the same bay, while individuals have a long life span and grow to a considerable size (Ambler \& Cañete 1991). Being competitively superior, $P$. chilensis excluded other species from the panels. However, single dominance did not occur due to the ability of several species such as, colonial ascidians, hydroids, and Ulva spp. growing on the surface of $P$. chilensis (A. Heidemann \& N. Valdivia pers. obs.), to use it as a secondary hard substratum.
Members of the genus Pyura offer complex habitats for diverse macrobenthic communities, acting as 'habitatengineers' (Sepúlveda et al. 2003, Castilla et al. 2004). When habitat-engineers are immune to disturbance and competition, their presence favours the reestablishment of other species after a disturbance event (Bertness \& Leonard 1997, Bruno et al. 2003), allowing those species to survive in very harsh conditions. As a result, maximum diversity can be observed at high disturbance levels when habitat-engineers are present (Hacker \& Gaines 1997). In the present study, P. chilensis was affected by the disturbance, and consequently its potential to act as facilitator for the settlement of other organisms is limited.

Dominance of Pyura chilensis decreased with a further increase in disturbance frequency, because the abundance of this species was disproportionately affected by disturbance treatments. This was probably due to its low recruitment and, compared to colonial growth forms, lower growth rate. Additionally, recruitment of $P$. chilensis is strongly seasonal, ranging from September to February (Ambler \& Cañete 1991). Disturbance applications for almost all treatments extended beyond this recruitment period; therefore, no new settlement of $P$. chilensis could be expected following the last disturbance events (4 in the case of the highest disturbance frequency). $P$. chilensis represents the prototype of a strong competitor with relatively low colonizing abilities. Based on the above (seasonal recruitment and dominance of $P$. chilensis during the study period), it can be suggested that during other periods (i.e. during the austral winter) the community succession may have been different, since diminished recruitment of $P$. chilensis may have reduced its effect as the dominant competitor.

By opening space for colonization, the disturbance treatments alleviated competition. Species richness and evenness increased in areas of the panels that were disturbed. This indicates that settlement of previously disturbed patches was mostly by different species to those found on undisturbed panels. Some of these newly colonizing species were not present on the panels before, while others increased in relative abundance, leading to an increase in evenness. This suggests that patch dynamics on the panels were a combination of colonization via pelagic propagules and lateral growth of adjacent species.

\section{Diversity declines towards the highest disturbance frequency}

For disturbance frequencies $>5$ times throughout the experimental period, the positive relationship between disturbance and species richness was reversed and 
mean species richness declined. This resulted in a unimodal relationship between disturbance frequency and species richness.

At the highest disturbance levels (i.e. $>5$ times) bare space often constituted over $20 \%$ of the panel surface. Competition for space therefore could play only a minor role, if at all. Under such harsh conditions, the community structure is mostly determined by the species' ability to colonize within the short period between disturbances (Connell 1978). Colonizing abilities of a species are expressed by high recruitment rates and fast growth. Colonial organisms, e.g. Diplosoma sp. in this study, are particularly likely to be good colonizers of small patches, as they can cover space by lateral growth faster than the dispersal stages of other species can settle and occupy the patch (Connell \& Keough 1985). Diplosoma sp. can vegetatively colonize approximately $40 \%$ of a previously disturbed non-isolated $25 \mathrm{~cm}^{2}$ patch within $1 \mathrm{wk}$ (A. Heidemann unpubl. data). Similarly, Turon \& Becerro (1992) observed that the species Diplosoma spongiforme (Giard 1872) presents a rapid growth rate compared with other ascidian species. Thus, it is suggested that Diplosoma sp., the second most abundant species on our panels, is a strong colonizer. Diplosoma sp. was the only species to slightly increase in abundance with increasing disturbance frequency, finally exceeding $P$. chilensis in percentage cover at the highest treatment level.

The diversity peak, which according to the IDH is predicted to occur at intermediate disturbance frequencies, was shifted towards higher frequencies, raising the question about the definition of intermediacy. Shea et al. (2004) pointed out that the intermediate disturbance frequency has to be defined in accordance with the rates of competitive exclusion. These rates depend in part on the population growth rates of the competing species (Huston 1979). Fouling communities at the study site, Bahía La Herradura, present high growth rates in comparison with other places of the Chilean coast (Viviani \& DiSalvo 1980). This characteristic of the system could offer an explanation to the disturbance-diversity relationship found in this study.

\section{Important prerequisites for the applicability of the IDH}

The results of the present study suggest that the alleviation of competition by disturbance allows the subordinate species to increase in abundance. At low disturbance frequencies, competitive exclusion seems to be responsible for the low diversity observed. The disturbance-induced suppression of the dominant species resulted in an increase of subordinate species. The characteristics of the principal competing species suggest that they differ in their competitive-colonizing abilities, supporting the idea that the trade-off between competitive abilities and colonizing abilities is required to observe a high species-coexistence under intermediate disturbance regimes (Petraitis et al. 1989, Collins \& Glenn 1997, Roxburgh et al. 2004). Contrarily, Thorp \& Cothran (1984) suggested that, in a balanced competitive network, intermediate levels of predation promote maximum diversity if predators switch among alternative prey, based on the their relative abundance. Although this hypothesis can be seen as an alternative to the dependence of the IDH on the trade-off between competitive and colonizing abilities, it has at present little experimental support.

Although recent theoretical studies explored the processes underlying the IDH (e.g. Roxburgh et al. 2004, Shea et al. 2004) empirical support for this hypothesis is still scarce (Mackey \& Currie 2001). In contrast to their conclusions, the results of the present study at Bahía La Herradura provide support for the IDH. We suggest that this is due to the fact that important prerequisites (existence of competitive exclusion and disturbanceinduced suppression of dominant competitors) for the validity of the IDH are fulfilled in the studied system. The concept of the IDH may not be suitable to explain the fluctuations of diversity in all systems and under all conditions, unless essential prerequisites are fulfilled. Recent empirical tests of the IDH support this conclusion. Lenz et al. (2004a,b) observed that in a situation where a species was dominant and suppressed by disturbance the unimodal disturbance-diversity relationship was evident, while in a situation where the same species only occurred in low numbers (due to low recruitment success) the IDH was not supported. Based on these arguments, we suggest that the IDH can only be used to explain the species coexistence in systems or conditions where competitively superior species are present, and these species are reduced in their abundance by disturbance. The fact that recent studies did not support the IDH as originally proposed by Connell (1978), indicates that important prerequisites for the IDH are not fulfilled in all studied communities, reducing the general applicability of the IDH.

Acknowledgements. We thank J. H. Connell and 2 anonymous reviewers whose invaluable comments have significantly improved the early version of this manuscript. M. Lenz provided important contributions to the discussion of this work. S. Boltaña, P. Ugalde, N. Vásquez, E. Macaya, I. Hinojosa and the boat crew at Universidad Católica del Norte gave field support. S. A. Navarrete and M. Cifuentes-Navarro helped with statistical information. We gratefully acknowledge review of the proofs for English language usage by $\mathrm{H}$. Sugden and Stephen Sampson. This study was part of the international research program GAME. Financial support for this study was provided by Foundation Mercator to M.W. and FONDECYT 1010356 to M.T. 


\section{LITERATURE CITED}

Acuña E, Moraga J, Uribe E (1989) La zona de Coquimbo: Un sistema nerítico de surgencia de alta productividad. Rev Com Perm Pac Sur Spec. No. 145-157

Ambler RP, Cañete JI (1991) Asentamiento y reclutamiento de Pyura chilensis Molina, 1782 (Urochordata: Ascidiacea) sobre placas artificiales suspendidas en Bahía La Herradura, Coquimbo, Chile. Rev Biol Mar 26:403-413

Aronson RB, Precht WF (1995) Landscape patterns of reef coral diversity: A test of the intermediate disturbance hypothesis. J Exp Mar Biol Ecol 192:1-14

Bertness D, Leonard G (1997) The role of positive interactions in communities: Lessons from intertidal habitats. Ecology 78:1976-1989

Bruno JF, Stachowicz JJ, Bertness D (2003) Inclusion of facilitation into ecological theory. Trends Ecol Evol 18:119-125

Buss LW (1979) Bryozoan overgrowth interactions - the interdependence of competition for space and food. Nature 281:475-477

Buss LW, Jackson JBC (1979) Competitive networks: Nontransitive competitive relationships in cryptic coral reefs environments. Am Nat 113:223-234

Castilla JC, Lagos NA, Cerda M (2004) Marine ecosystem engineering by the alien ascidian Pyura praeputialis on a mid-intertidal rocky shore. Mar Ecol Prog Ser 268: 119-130

Collins SL, Glenn SM (1997) Intermediate disturbance and its relationship to within- and between patch dynamics. NZ J Ecol 21:103-110

Connell JH (1961) The influence of interspecific competition and other factors on the distribution of the barnacle Chthamalus stellatus. Ecology 42:710-723

Connell JH (1978) Diversity in tropical rain forests and coral reefs. Science 199:1302-1310

Connell JH, Keough MJ (1985) Disturbance and patch dynamics of subtidal marine animals on hard substrata. In: Pickett STA, White PS (eds) The ecology of natural disturbance and patch dynamics. Academic Press, Orlando, FL, p 125-151

Connolly SR, Muko S (2003) Space preemption, size-dependent competition, and the coexistence of clonal growth forms. Ecology 84:2979-2298

Daneri G, Dellarossa V, Quiñones R, Jacob B, Montero P, Ulloa O (2000) Primary production and community respiration in the Humboldt Current System off Chile and associated oceanic areas. Mar Ecol Prog Ser 197:41-49

Death RG, Winterbourn MJ (1995) Diversity patterns in stream benthic invertebrate communities: the influence of habitat stability. Ecology 76:1446-1460

Flöder S, Sommer U (1999) Diversity in planktonic communities: an experimental test of the intermediate disturbance hypothesis. Limnol Oceanogr 44:1114-1119

Grime JP (1977) Evidence for the existence of 3 primary strategies in plants and its relevance to ecological and evolutionary theory. Am Nat 111:1169-1194

Hacker S, Gaines S (1997) Some implications of direct positive interactions for community species diversity. Ecology 78 : 1990-2009

Huston MA (1979) A general hypothesis of species diversity. Am Nat 113:81-101

Kondoh M (2001) Unifying the relationships of species richness to productivity and disturbance. Proc R Soc Lond B 268:269-271

Lake PS, Doeg TJ, Marchant R (1989) Effects of multiple disturbance on macroinvertebrate communities in the Acheron river, Victoria. Aus J Ecol 14:507-514
Lenz M, Molis M, Wahl M (2004a) Experimental test of the intermediate disturbance hypothesis: frequency of emersion on fouling communities. J Exp Mar Biol Ecol 305: $247-266$

Lenz M, Molis M, Wahl M (2004b) Testing the intermediate disturbance hypothesis: response of fouling communities to various levels of emersion intensity. Mar Ecol Prog Ser 278:53-65

Lubchenco J (1978) Plant species diversity in a marine intertidal community: importance of herbivore food preference and algal competitive abilities. Am Nat 112:23-39

Mackey RL, Currie DJ (2000) A re-examination of the expected effects of disturbance on diversity. Oikos 88: 483-493

Mackey RL, Currie DJ (2001) The diversity-disturbance relationship: is it generally strong and peaked? Ecology 82: 3479-3492

McCabe DJ, Gotelli NJ (2000) Effects of disturbance frequency, intensity, and area on assemblages of stream macroinvertebrates. Oecologia 124:270-279

Miller TE (1982) Community diversity and interactions between the size and frequency of disturbance. Am Nat 120: $533-536$

Mook DH (1981) Effects of disturbance and initial settlement on fouling community structure. Ecology 62:522-526

Moraga J, Olivares J (1993) Variabilidad térmica de la Bahía La Herradura de Guayacán, Coquimbo, Chile. Estud Oceanol Fac Recur Mar Univ Antofagasta 12:29-36

Morales CE, Blanco JL, Braun M, Reyes H, Silva N (1996) Chlorophyll-a distribution and associated oceanographic conditions in the upwelling region off northern Chile during the winter and spring 1993. Deep-Sea Res Part I 43: $267-289$

Navarrete SA, Castilla JC (2003) Experimental determination of predation intensity in an intertidal predator guild: dominant versus subordinate prey. Oikos 100: 251-262

Nielsen KJ, Navarrete SA (2004) Mesoscale regulation comes from the bottom-up: intertidal interactions between consumers and upwelling. Ecol Lett 7:31-41

Paine R, Levin SA (1981) Intertidal landscapes: disturbance and the dynamics of pattern. Ecol Monogr 51:145-178

Petraitis PS, Latham RE, Niesenbaum RA (1989) The maintenance of species diversity by disturbance. Q Rev Biol 64: $393-418$

Proulx M, Mazumder A (1998) Reversal of grazing impact on plant species richness in nutrient-poor vs. nutrient-rich ecosystems. Ecology 79:2581-2592

Roxburgh SH, Shea K, Wilson JB (2004) The intermediate disturbance hypothesis: patch dynamics and mechanisms of species coexistence. Ecology 85:359-371

Satterthwaite FE (1946) An approximate distribution of estimates of variance components. Biometrics Bull 2: $110-114$

Sepúlveda R, Cancino JM, Thiel M (2003) The peracarid epifauna associated with the ascidian Pyura chilensis (Molina, 1782) (Ascidiacea: Pyuridae). J Nat Hist 13: $1555-1569$

Shea K, Roxburgh SH, Rauschert SJ (2004) Moving from pattern to process: coexistence mechanisms under intermediate disturbance regimes. Ecol Lett 7:491-508

Silva N, Konow D (1975) Contribución al conocimiento de las masas de agua en el Pacífico Sudoriental, (Expedición Krill, Crucero 3-4, Julio-Agosto 1974). Rev Com Perm Pac Sur 3:63-75

Sokal RR, Rohlf RJ (1995) Biometry, 3rd edn. Freeman and Company, New York 
Takesue RK, van Geen A, Carriquiry JD, Ortiz E and 10 others (2004) Influence of coastal upwelling and El NiñoSouthern Oscillation on nearshore water along Baja California and Chile: shore-based monitoring during 1997-2000. J Geophys Res C 109:1-14

Thorp JH, Cothran ML (1984) Regulation of freshwater community structure at multiple intensities of dragonfly predation. Ecology 65:1546-1555

Tilman D (1994) Competition and biodiversity in spatially structured habitats. Ecology 75:2-6

Turon X, Becerro MA (1992) Growth and survival of several ascidian species from the northwestern Mediterranean. Mar Ecol Prog Ser 82:235-247

Underwood AJ (1997) Experiments in ecology. Their logical design and interpretation using analysis of variance. Cambridge University Press, Cambridge

Viviani CA, DiSalvo LH (1980) Biofouling in a north-central

Editorial responsibility: Otto Kinne (Editor-in-Chief), Oldendorf/Luhe, Germany
Chilean coastal bay. Proc 5th Int Congr Mar Corr Foul, Barcelona, p 69-74

White PS, Pickett STA (1985) Natural disturbance and patch dynamics: an introduction. In: Pickett STA, White PS (eds) The ecology of natural disturbance and patch dynamics. Academic Press, Orlando, FL, p 3-13

Wieters EA, Kaplan DM, Navarrete SA, Sotomayor A, Largier J, Nielsen KJ, Véliz F (2003) Alongshore and temporal variability in chlorophyll a concentration in Chilean nearshore waters. Mar Ecol Prog Ser 249:95-105

Wootton JT (1998) Effects of disturbance on species diversity: a multitrophic perspective. Am Nat 152:803-825

Yu DW, Wilson HB (2001) The competition-colonization trade-off is dead; long live the competition-colonization trade-off. Am Nat 158:48-63

Zar JH (1999) Biostatistical analysis, 4th edn. Prentice Hall, Upper Saddle River, NJ

Submitted: October 13, 2004; Accepted: April 21, 2005

Proofs received from author(s): August 1, 2005 